\title{
Nuevos horizontes de vivienda, población y empleo asociados a la capitalidad política regional. Los casos de Mérida y Pamplona (1980-2011)
}

\section{New horizons on housing, population and employment linked to being a regional political capital. The cases of Mérida and Pamplona (1980-2011)}

\author{
Antonio J. Palacios García*
}

\section{INTRODUCCIÓN}

La organización política y administrativa del estado en Comunidades Autónomas derivada de la transición democrática ha traído consigo numerosas transformaciones de diversa índole, especialmente en aquellas ciudades escogidas para asumir las funciones capitalinas de dichas entidades. Aunque la disparidad existente entre ellas es evidente, tanto en términos demográficos como económicos, lo cierto es que las capitales autonómicas son el reflejo de la descentralización política y administrativa en España.

En muchas ocasiones se ha indicado como el modelo político-administrativo que se ha ido desarrollando en las comunidades ha respondido a pautas centralizadoras, en el que las capitales son sedes gubernamentales regionales

\footnotetext{
* Profesor Contratado Doctor en el Departamento de Geografía de la Universidad Autónoma de Madrid (antonio.palacios@uam.es).

Este texto se enmarca en el proyecto de investigación "Las ciudades españolas en la etapa autonómica (1978-2008). Dinámicas, procesos y políticas". Ref. CSO 2009-11261 (Subprograma GEOG), del Ministerio de Ciencia e Innovación.
} 
(Presidencia, Consejerías y Parlamento) y han asumido competencias de todo tipo que directamente han supuesto un incremento del poder y la creación de numerosos entes institucionales, e indirectamente han producido aumentos de su centralidad por la instalación en ellas de numerosas funciones de rango elevado (Serrano, 2002, p. 148). Como contrapartida, esto ha supuesto un incremento considerable de los llamados costes de capitalidad, derivados de la congestión o de la concentración de problemas sociales por ejemplo, y de centralidad (sustitución de actividades productivas o exenciones fiscales a las actividades administrativas) que han debido asumir, en casi todos los casos, las arcas municipales (Bosch, Espasa y Montolio, 2011, p. 84). Son una excepción, por poner algunos ejemplos notables, los casos de Pamplona, que recibe una compensación establecida en la Ley Foral 16/1997 y Vitoria, que recientemente se ha visto beneficiada por la aprobación del llamado canon de capitalidad ( 5 millones de euros al año) por ser la sede de las instituciones comunes de la comunidad autónoma vasca.

Aun asumiendo la existencia de disfuncionalidades y debilidades en la determinación de las capitales, en el sistema de transferencia de competencias y, en definitiva, con todo lo relativo al «hecho autonómico», lo que resulta innegable es que las transformaciones urbanas y socioeconómicas acontecidas en estas últimas décadas en estos ámbitos han sido cuantiosas y de naturaleza diversa.

El objetivo de esta aportación es mostrar en qué han consistido dichas transformaciones en dos ciudades medias como Pamplona y Mérida y cómo se han materializado en aspectos demográficos (evolución de la población, nacimientos, defunciones y crecimiento natural), laborales (evolución de la población ocupada por grandes y específicos sectores económicos y población vinculada) y residenciales (evolución en el número de viviendas), como consecuencia de la nueva capitalidad política (la presencia de las administraciones autonómicas en la capital regional). Para ello partimos de dos premisas. La primera es la referida al creciente protagonismo alcanzado por las ciudades de dimensión y rango intermedios dentro de los sistemas urbanos por sus implicaciones económicas, demográficas y sociales, especialmente significativas en su entorno regional (Caravaca, I.; González, G. y Mendoza, A., 2007, p. 132). En este sentido, los dos estudios de caso responden perfectamente a los dos rasgos definitorios y complementarios de este tipo de ciudades que plantea el profesor Ricardo Méndez (2009, p. 22), esto es, se tratan de centros de tamaño y rango intermedios dentro del sistema urbano, y además actúan como intermediarios entre la gran ciudad y los espacios rurales circundantes. La segunda es aquella que pone el acento en la redistribución espacial de los 
sectores de actividad, las empresas y los empleos ${ }^{1}$, vinculada a la influencia de un factor de localización que podríamos considerar como tradicional, como es la capitalidad. En este sentido, tanto Mérida como Pamplona han ejercido (en su papel de ciudades intermedias ${ }^{2}$ ) como proveedores de bienes y servicios especializados además de actuar también como centros de poder político y de la administración (Méndez et al., 2008, p. 231).

\section{ASPECTOS PROCEDIMENTALES}

Los aspectos procedimentales se basan en una metodología de estudios de caso. Dado que esta aportación se incardina en un proyecto de investigación, que en esta fase de desarrollo se ha centrado en las capitales autonómicas, se han seleccionado dos ejemplos representativos de ciudades intermedias, Pamplona como capital autonómica de régimen foral (Vitoria también lo es) y Mérida como capital autonómica implantada en ciudades no capitales provinciales (Santiago también lo es). El nexo de unión entre ellas, y por tanto el motivo de su elección, es que en ambos casos, se trata de centros vitales para la gestión política y administrativa de sus respectivas regiones, dado que en ellas se ubica el gobierno regional, ejecutivo y legislativo. Este hecho se ve afianzado aún más si cabe en el caso de Pamplona dado que posee además la Delegación del Gobierno y todas las delegaciones de ámbito provincial y autonómico.

De cualquier modo, no podemos obviar las significativas diferencias que presentan ambas ciudades que tienen que ver en primer lugar con su propia concepción. Así, en el caso de Mérida su condición actual no coincide con la capital provincial que es Badajoz (ni con la otra capital provincial de la región que es Cáceres) aunque sí cuenta con una dilatada tradición como capital del Imperio Romano en la Península. Esto es, la capitalidad supone una resituación en el sistema regional (Ganau y Vilagrasa, 2003, p. 39), con un triángulo de fuerzas entre las dos capitales provinciales y Mérida. Por su parte, Pamplona se ha caracterizado tradicionalmente por ser el centro neurálgico y el pilar político, demográfico y económico básico de la cuenca del mismo nombre (configurada por más de una veintena de municipios y una población de más de

\footnotetext{
${ }^{1}$ En las obras de Méndez et al. (2006) y Caravaca y González (2009) se hace referencia a la importancia del aprovechamiento del capital social como una de las cuestiones esenciales para el desarrollo de estas ciudades.

${ }^{2}$ Existe un número elevado de trabajos referidos a la importancia de las ciudades medias. En la obra de Capel (2009) se puede encontrar un repaso general a los mismos.
} 
300.000 habitantes). Entonces, a diferencia de Mérida, la capitalidad supone un afianzamiento en su papel regional. A ello habría que añadirle el hecho de que cuente con Carta de Capitalidad desde $1997^{3}$ (en Mérida se está trabajando en ello desde el Ayuntamiento y la Junta de Extremadura ${ }^{4}$ ), lo que confiere al ayuntamiento una singularidad cualitativa respecto a otras entidades locales. Esto a su vez supone una contrapartida presupuestaria con un régimen de financiación especial, vinculada a lo que algunos autores han denominado los costes de centralidad y de capitalidad relacionados con la presencia en la ciudad de instituciones del gobierno autonómico y estatal (Alli, 2001, p. 54).

Del mismo modo, en ambos casos se ponen de manifiesto diferencias significativas en cuanto al volumen demográfico respecto al total regional. Así, mientras Pamplona que cuenta con unos 200.000 habitantes aglutina más de un tercio de los navarros, en Mérida solo residen unos 50.000 habitantes que tan solo suponen el 5\% de los extremeños y el $8 \%$ de los pacenses.

Aunque en ambos casos hablamos de ciudades medias o intermedias, lo cierto es que subsisten diferencias notables también en términos económicos, que se concretan en unas dinámicas económicas diferenciadas desde el momento en que una de ellas dispone de Régimen Foral y la otra no. Así por ejemplo, el Anuario Estadístico de La Caixa 2012 establece un Índice de Actividad Económica (que se obtiene en función del impuesto correspondiente al total de actividades económicas empresariales -industriales, comerciales y de servicios- y profesionales) para Pamplona de 1015 que casi multiplica por diez el valor obtenido para Mérida (102). Por otro lado, si se atiende a los indicadores de renta, mientras que Mérida posee unos 16.000€ per cápita, Pamplona casi duplica ese valor (tiene aproximadamente $30.000 €$ ). En ambos casos, se trata de cifras que son muy similares a las que poseen sus respectivas comunidades.

Partiendo de estas cuestiones, la hipótesis de partida sería la de demostrar que la capitalidad política en ambos casos ha supuesto transformaciones en la dinámica demográfica y residencial, a pesar de los contrastes existentes entre las mismas. Esta cuestión será abordada desde una triple perspectiva. Por un lado, a partir del análisis de la dinámica demográfica puesto que los cambios

${ }^{3}$ Ley Foral 16/1997, de 2 de diciembre, por la que se establece la Carta de Capitalidad de la ciudad de Pamplona, dotando al Ayuntamiento de un complemento singular a su régimen ordinario de financiación.

${ }^{4}$ Hay que tener en cuenta que la Ley 51/2002, de 27 de diciembre, de reforma de la Ley 39/1988, de 28 de diciembre, reguladora de las Haciendas Locales, ya establece un modelo de financiación diferente para los municipios de 75.000 habitantes o capitales de provincia o autonómicas. 
tienen que ver con el grado de concentración de la población que, tal y como plantea el profesor Serrano (1984) es el elemento indicativo importante que permite deducir su significación real dentro de la misma. La pregunta clave sería, ¿han disfrutado estas capitales de un crecimiento demográfico primado e interrumpido por el hecho de haber sido elegidas como capitales autonómicas? Por otro lado, a partir del análisis de la evolución de la población activa, puesto que esos cambios tienen mucho que ver con la localización de los nuevos centros de poder (poderes legislativos y ejecutivos, órganos e instituciones) que han supuesto un aumento de la centralidad y la posibilidad de creación de numerosos puestos de trabajo directos o indirectos. Por tanto, las cuestiones aquí serían, ¿qué ha supuesto en términos de empleo la capitalidad?, o ¿cómo ha evolucionado el empleo público en ambas ciudades?, o ¿cuál ha sido el comportamiento del empleo en otras actividades inducidas por la capitalidad como la hostelería y el ocio? Por último, también resultan de interés las transformaciones residenciales acontecidas en ambos espacios urbanos. Ganau y Vilagrasa (2003) en su estudio sobre las ciudades medias españolas anticipan algunas cuestiones incluyendo a Pamplona en el grupo de ciudades medias en entornos metropolitanos, con un proceso de desconcentración absoluta en el que el centro decrece en términos demográficos y la corona metropolitana crece, además de contar con un desarrollo periurbano de baja densidad. Por su parte, Mérida es incluida en el grupo de ciudades situadas en lugares estratégicos de los corredores de transporte, incardinada en el sistema polinuclear de ciudades extremeñas y en el eje de entrada a Portugal. Además se caracteriza por haber iniciado un proceso de descentralización urbana en el que crecen tanto el centro como la corona periurbana. Así, las cuestiones a investigar serían, ¿cómo ha evolucionado la vivienda desde los ochenta hasta ahora?, ¿cuáles han sido las dinámicas residenciales? o, ¿ha sido un crecimiento planificado y ordenado?

Para dar respuesta a estas preguntas se ha recurrido a numerosas y diversas fuentes documentales, tanto cuantitativas como cualitativas. Dado el amplio periodo de estudio (desde 1970 hasta la actualidad), han sido de gran interés para el análisis de la dinámica demográfica y la vivienda (población, varones, mujeres, nacimientos, defunciones, población activa, población vinculada y viviendas) los Censos de Población y Vivienda del Instituto Nacional de Estadística (INE) de los años 1970, 1981, 1991 y 2001, que han sido complementados en los periodos intercensales por la información suministrada por los Institutos de Estadística de Extremadura (IEEX) y Navarra (IEN). Por otro lado, los datos de población activa de 2011 proceden de la Tesorería General de la Seguridad Social (TGSS), mientras que el número de viviendas de ese 
mismo año se ha extraído de los ficheros de la Dirección General del Catastro para el caso de Mérida y del Servicio de Riqueza Territorial del Catastro de Navarra para el municipio de Pamplona. Además de lo anterior, se han llevado a cabo búsquedas selectivas en internet (bibliográficas y documentales) y se han realizado una serie de breves entrevistas con aquellos responsables de organismos implicados en las cuestiones estudiadas.

La combinación de toda la información extraída a partir de las diferentes fuentes constituye el grueso de esta investigación. Cabe destacar en este sentido las dificultades encontradas para la obtención de los datos estadísticos a pesar de que muchos de ellos tienen como procedencia un mismo organismo. Por ejemplo, mientras que los datos del Censo de 1970 se muestran en la página web del INE con un nivel de desagregación municipal, los del Censo de 1981 sólo se muestran a nivel nacional y es necesario llevar a cabo una petición a medida para obtener los datos municipales. A ello, habría que añadir las disparidades existentes en los criterios de catalogación entre censos, puesto que no siempre se recoge con las mismas rúbricas ni las mismas clasificaciones, los datos referidos a la población española. Por ejemplo, en el Censo de 1981, los datos de la población activa aparecen de acuerdo a la Clasificación Nacional de Actividades Económicas (CNAE74) a dos dígitos, mientras que el Censo de 1991 utiliza la CNAE93 y la Seguridad Social utiliza la CNAE09 para su clasificación de 2011. Del mismo modo, la obtención de los ocupados en la administración pública o en las actividades de hostelería y ocio ha supuesto tener que utilizar rúbricas diferentes en función de los años de estudio. Todo ello pone de manifiesto, por un lado la dificultad que todavía hoy existe a la hora de obtener información estadística de carácter público, y por otro, la existencia de disfuncionalidades cuando se pretenden comparar datos de fuentes y años diferentes.

3. LAS TRANSFORMACIONES DEMOGRÁFICAS Y LABORALES COMO EJES DEL DESARROLLO EN LAS CIUDADES DE MÉRIDA Y PAMPLONA

\subsection{La dinámica demográfica}

Los resultados de esta investigación parecen poner de manifiesto, tanto en Mérida como en Pamplona, transformaciones de índole puramente demográfica que podrían estar vinculadas a la capitalidad y que tienen que ver con los indicadores de volumen de población, movimientos naturales y migraciones.

Así, la tabla 1 corrobora, no sin matices, las palabras del profesor Serrano que allá por finales de los ochenta planteaba que el crecimiento de ambas ciu- 
TABLA 1

EVOLUCIÓN DE LA DINÁMICA DEMOGRÁFICA

\begin{tabular}{lrrrrrr}
\hline & Total & Hombres & Mujeres & Nacimientos & Defunciones & $\begin{array}{c}\text { Crecimiento } \\
\text { Natural }\end{array}$ \\
\hline 1970 & 40.059 & 19.706 & 20.353 & 1.328 & 237 & 1.091 \\
1981 & 41.027 & 20.023 & 21.004 & 739 & 330 & 409 \\
1986 & 51.641 & 25.109 & 26.532 & --- & --- & -- \\
1991 & 49.284 & 24.141 & 25.143 & 715 & 378 & 337 \\
1996 & 51.830 & 25.381 & 26.449 & 566 & 384 & 182 \\
2001 & 51.056 & 24.857 & 26.199 & 615 & 416 & 199 \\
2006 & 53.915 & 26.240 & 27.675 & 693 & 416 & 277 \\
2011 & 57.797 & 28.186 & 29.611 & 697 & 422 & 275 \\
\hline & & & & & \\
\hline 1970 & 147.168 & 70.527 & 76.642 & 4.801 & 1.447 & 3.354 \\
1981 & 177.906 & 85.866 & 92.040 & 2.518 & 1.315 & 1.203 \\
1986 & 178.439 & 86.125 & 92.314 & 1.854 & 1.381 & 473 \\
1991 & 180.372 & 86.636 & 93.736 & 1.834 & 1.435 & 399 \\
1996 & 166.279 & 79.101 & 87.178 & 1.437 & 1.565 & -128 \\
2001 & 186.245 & 89.077 & 97.168 & 2.020 & 1.498 & 522 \\
2006 & 195.769 & 93.775 & 101.994 & 2.138 & 1.625 & 513 \\
2011 & 197.932 & 94.642 & 103.290 & 1.859 & 1.694 & 165 \\
\hline & & & & \\
\hline
\end{tabular}

Fuente: Elaboración propia a partir de información del Instituto Nacional de Estadística (INE), del Instituto de Estadística de Extremadura (IEEX) y del Instituto de Estadística de Navarra (IEN).

dades había sido primado e ininterrumpido por el hecho de ser capitales provinciales. Como se puede apreciar, desde el Censo de $1981^{5}$ hasta hoy día, Mérida tiene aproximadamente 16.000 habitantes más, mientras que Pamplona ha aumentado en 20.000 efectivos su población. Dicho de otro modo, si tomamos como base 100 los datos de 1981, en Mérida hoy tenemos 138 y en Pamplona 111. Ahora bien, si comparamos estas cifras a escala regional, ob-

${ }^{5}$ Tomamos como referencia el Censo de Población y Vivienda de 1981 ya que la capitalidad le llega a Mérida el 25 de febrero de 1983 (Ley Orgánica 1/1983, Estatuto de Autonomía de Extremadura), mientras que a Pamplona el 10 de agosto de 1982 (Ley Orgánica 13/1982, de 10 de agosto, de Reintegración y Amejoramiento del Régimen Foral). 
servaremos que el crecimiento de la capital extremeña ha supuesto más de una tercera parte del experimentado por la comunidad autónoma en su totalidad, que ha pasado de 1.064.976 habitantes en 1981 a 1.109.367 en la actualidad. Sin embargo, en el caso pamplonica, los 20.000 nuevos residentes han sido solo menos de una quinta parte del crecimiento total de la comunidad navarra, que ha pasado de 509.002 habitantes en 1981 a más de 642.051 en 2011. Estos datos ya son indicativos de las diferentes dinámicas existentes entre ambas ciudades y sus respectivas comunidades autónomas.

A rasgos generales, las restantes variables demográficas (nacimientos, defunciones y crecimiento natural) siguen una pauta similar a la del conjunto de la población, tanto en Mérida como en Pamplona. Ahora bien, no es menos cierto que también existen diferencias en función de los periodos de estudio y de las variables analizadas. Así, si consideramos las tasas de variación (Valor final / Valor inicial menos 1) tal y como aparecen en la tabla 2, observaremos incrementos de población del 44\% entre 1970 y la actualidad en Mérida y del $34 \%$ en Pamplona. Estos datos no se corresponden con los obtenidos a nivel

TABLA 2

EVOLUCIÓN DE LA DINÁMICA DEMOGRÁFICA [TASAS DE VARIACIÓN]

\begin{tabular}{lrrccc}
\hline & Total & Hombres & Mujeres & Nacimientos & Defunciones \\
\hline$[1970-2011]$ & $44 \%$ & $43 \%$ & $45 \%$ & $-48 \%$ & $78 \%$ \\
{$[1970-1981]$} & $2 \%$ & $2 \%$ & $3 \%$ & $-44 \%$ & $39 \%$ \\
{$[1981-1991]$} & $20 \%$ & $21 \%$ & $20 \%$ & $-3 \%$ & $15 \%$ \\
{$[1991-2001]$} & $4 \%$ & $3 \%$ & $4 \%$ & $-14 \%$ & $10 \%$ \\
{$[2001-2011]$} & $13 \%$ & $13 \%$ & $13 \%$ & $13 \%$ & $1 \%$ \\
\hline$[1970-2011]$ & $34 \%$ & $34 \%$ & $35 \%$ & $-61 \%$ & $17 \%$ \\
{$[1970-1981]$} & $21 \%$ & $22 \%$ & $20 \%$ & $-48 \%$ & $-9 \%$ \\
{$[1981-1991]$} & $1 \%$ & $1 \%$ & $2 \%$ & $-27 \%$ & $9 \%$ \\
{$[1991-2001]$} & $3 \%$ & $3 \%$ & $4 \%$ & $10 \%$ & $4 \%$ \\
{$[2001-2011]$} & $6 \%$ & $6 \%$ & $6 \%$ & $-8 \%$ & $13 \%$ \\
\hline
\end{tabular}

Fuente: Elaboración propia a partir de información del INE, del IEEX y del IEN.

Estudios Geográficos, Vol. LXXV, 276, pp. 311-345, enero-junio 2014

ISSN: 0014-1496, eISSN: 1988-8546, doi: 10.3989/estgeogr.201408 
regional en el caso de Extremadura, donde la tasa para el mismo periodo es negativa $(-5,5 \%)$. Eso pone en situación el crecimiento de Mérida por efecto de la capitalidad. Sin embargo, en Navarra la tasa de variación es muy similar a la de la capital (37\%).

Por otro lado, la variación negativa en los nacimientos ha sido del $61 \%$ en Pamplona y del 48\% en Mérida, mientras que la variación positiva de las defunciones es más acusada en Mérida (78\%) que en Pamplona (17\%). De cualquier modo, la dinámica demográfica general está en relación con el paulatino envejecimiento de la población, el descenso de los nacimientos y el aumento de las defunciones, todos ellos rasgos característicos de sociedades desarrolladas.

Por último, el componente migratorio ha sido calculado (ante la ausencia de fuentes directas para esta variable) recurriendo a la ecuación compensatoria que permite estimar la migración como un residuo, aunque los saldos migratorios no ofrecen ninguna información sobre la intensidad de los flujos, ni sobre su procedencia o destino. La ecuación es la siguiente (siendo SM el saldo migratorio, $\mathrm{P}$ la población, $\mathrm{N}$ los nacimientos y $\mathrm{D}$ las defunciones):

$$
\mathrm{SM}^{\mathrm{t}, \mathrm{t}+\mathrm{x}}=\mathrm{P}^{\mathrm{t}+\mathrm{x}}-\mathrm{P}^{\mathrm{t}}-\mathrm{N}^{\mathrm{t}, \mathrm{t}+\mathrm{x}}+\mathrm{D}^{\mathrm{t}, \mathrm{t}+\mathrm{x}}
$$

La figura 1 muestra el saldo migratorio comparado de la Comunidad Foral de Navarra y de Pamplona para los diferentes periodos de estudio. La ausencia de información referida a los nacimientos y defunciones en Extremadura y Mérida ha hecho imposible realizar este mismo cálculo en este caso. De cualquier modo, el gráfico pone de manifiesto la importancia del componente migratorio en la dinámica demográfica para el periodo 1970-2011 tanto para la comunidad como para el municipio. Por ejemplo, en Pamplona, si la población total ha aumentado en casi 50.000 efectivos en ese periodo (de 147.000 habitantes en 1970 ha pasado a 197.000 en 2011), y el saldo migratorio, calculado según la ecuación anterior, da como resultado casi 30.000, viene a significar que un $60 \%$ de esa dinámica poblacional está vinculada directamente a los movimientos migratorios. Aunque los valores son diferentes para la comunidad, el peso del componente migratorio es muy similar.

Ahora bien, como muestra el gráfico, las diferencias han sido notables entre unos decenios y otros, siendo especialmente significativo el descenso en el saldo migratorio entre 1981 y 1991 para la capital (que también se corresponde con un leve incremento poblacional de la ciudad de 3.000 habitantes aproximadamente), y ya desde 1970 para la comunidad. En Pamplona son, sin lugar a dudas, los periodos anteriores a la capitalidad (1970-1981) y el más cercano en el tiempo (2001-2011), los que explican su dinámica demográfica, 
FIGURA 1

\section{SALDO MIGRATORIO (POR ECUACIÓN FUNDAMENTAL)}

EN NAVARRA Y PAMPLONA

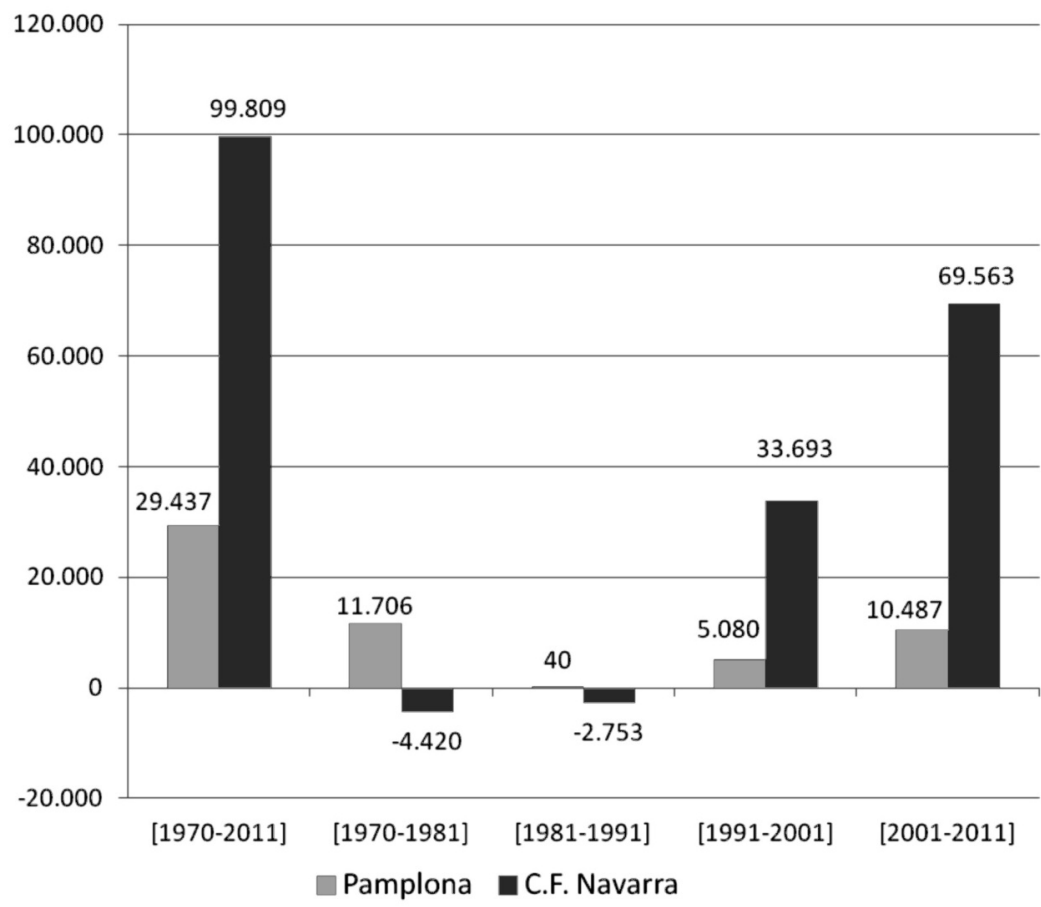

Fuente: Elaboración propia a partir de información del INE y del IEN.

dado que se caracterizan por fuertes crecimientos poblacionales de $30.000 \mathrm{y}$ 11.000 habitantes respectivamente. Esto supone que una tercera parte del total del primer periodo tiene que ver con los movimientos migratorios (mayor influencia de la capitalidad) y que desde 2001 el saldo migratorio explica la totalidad del crecimiento absoluto de la población (por atracción de población extranjera). Por su parte, en el conjunto regional son las dos últimas décadas las que están caracterizadas por un incremento mayor de población (36.000 y 84.000 habitantes respectivamente). Ello supone que entre el 70 y el $90 \%$ del crecimiento está vinculado con las migraciones (intrarregionales y, sobre todo, extranjeras en su mayor parte). 


\subsection{La estructura socio-profesional por grandes sectores económicos}

En segundo lugar, las transformaciones vinculadas a la capitalidad también podrían tener su reflejo en la estructura de la población activa por sectores económicos. Partimos de la base de que se debe haber producido un incremento en los ocupados en la administración pública en ambos casos, a los que podríamos añadir también un incremento en los trabajadores de actividades vinculadas a la capitalidad como son la construcción o las de hostelería y ocio. Para ello, hemos clasificado la población ocupada en diferentes momentos (1970, 1981, 1991, 2001 y 2011) por sectores económicos (primario, secundario y terciario). Además, se ha procedido a clasificar de forma independiente los ocupados en los subsectores de construcción, administración pública y hostelería y ocio por entender que han podido ser los que más (que no los únicos probablemente) se hayan podido ver modificados por efecto de la capitalidad. Hay que decir que las dificultades han sido notables en este punto puesto que los diferentes censos y fuentes de información utilizadas no siempre denominan de la misma manera a la población ocupada. Por ello, el análisis y las conclusiones han podido verse alteradas en mayor o menor medida ante la ausencia de criterios uniformes en todo el periodo de estudio.

La tabla 3 muestra claramente el proceso de terciarización que ha caracterizado la economía de ambas comunidades autónomas y ciudades en el periodo de estudio. La tendencia es aún más acusada en el caso de Mérida que llega hasta un $88 \%$ de población ocupada en actividades de servicios en la actualidad, frente a un $82 \%$ en el caso de Pamplona. En ninguna de las dos comunidades de referencia se alcanzan valores tan elevados, aunque la tendencia general sea similar. Es posible que la capitalidad, junto con su propio carácter urbano, haya influido en un crecimiento mayor de este sector.

Por su parte, los datos reflejan la reducción significativa de los trabajadores industriales en ambas ciudades, siendo poco acusado en Navarra y positivo para el caso de Extremadura. En la ciudad de Mérida podría deberse en buena medida a la pérdida de importancia de la industria de transformación vinculada al Plan Badajoz. Tal y como reflexiona José Fernández Vidal, secretario autonómico de CSI-CSIF, en el periódico HOY (18/5/2008), «en la región no hay tejido industrial fuerte ni empresas grandes; la Junta de Extremadura es la principal empresa a la hora de crear trabajo». Aunque en Pamplona se ha reducido significativamente su peso porcentual (46,4\% en 1970) todavía aglutina a más de 16.000 trabajadores que suponen casi una quinta parte del total. En el conjunto de la comunidad foral el peso de la industria todavía es significativo con más de un tercio del total de ocupados en dicho sector. 


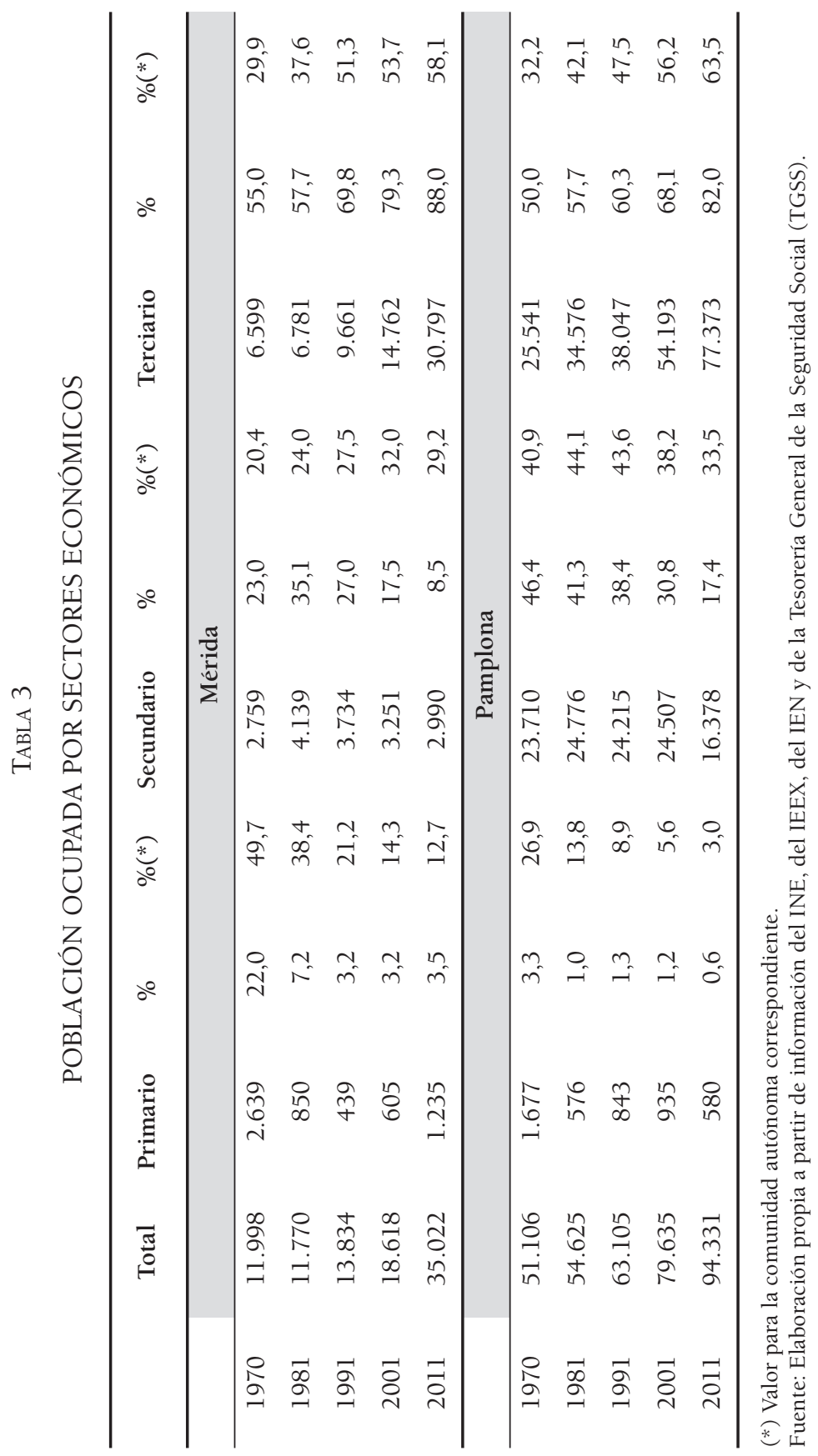

Estudios Geográficos, Vol. LXXV, 276, pp. 311-345, enero-junio 2014

ISSN: 0014-1496, eISSN: 1988-8546, doi: 10.3989/estgeogr.201408 
Por último, y como no podía ser de otro modo, se puede apreciar el descenso drástico de los trabajadores en el sector primario en ambas comunidades (aunque con diferencias en los valores porcentuales en la actualidad, puesto que en Navarra aglutina al 3,0\% de los ocupados y en Extremadura a casi el 13\%). En las ciudades el retroceso de los ocupados en este sector también es notable, aunque habría que destacar su escasa importancia tradicional en el cómputo total en el caso de Pamplona (3,3\% en 1970 frente al 22\% de Mérida en ese mismo año).

Por otro lado, si analizamos las tasas de variación por periodos y sectores (figuras 2 y 3 ) y las comparamos con los resultados obtenidos en las respectivas comunidades autónomas, podemos destacar varias cuestiones de interés:

a) En primer lugar, el crecimiento del total de ocupados entre el comienzo y el final del periodo de estudio. En ambas comunidades esta cifra ronda los 80.000, con unas tasas de variación de entre el 30 y el $47 \%$. Sin embargo, Mérida presenta un incremento del 192\% (11.998 ocupados en 1970 a 35.022 en 2011) frente al más modesto 85\% de Pamplona (51.106 ocupados en 1970 a 94.331 en 2011).

\section{FIGURA 2}

POBLACIÓN OCUPADA POR SECTORES ECONÓMICOS EN MÉRIDA [TASAS DE VARIACIÓN]

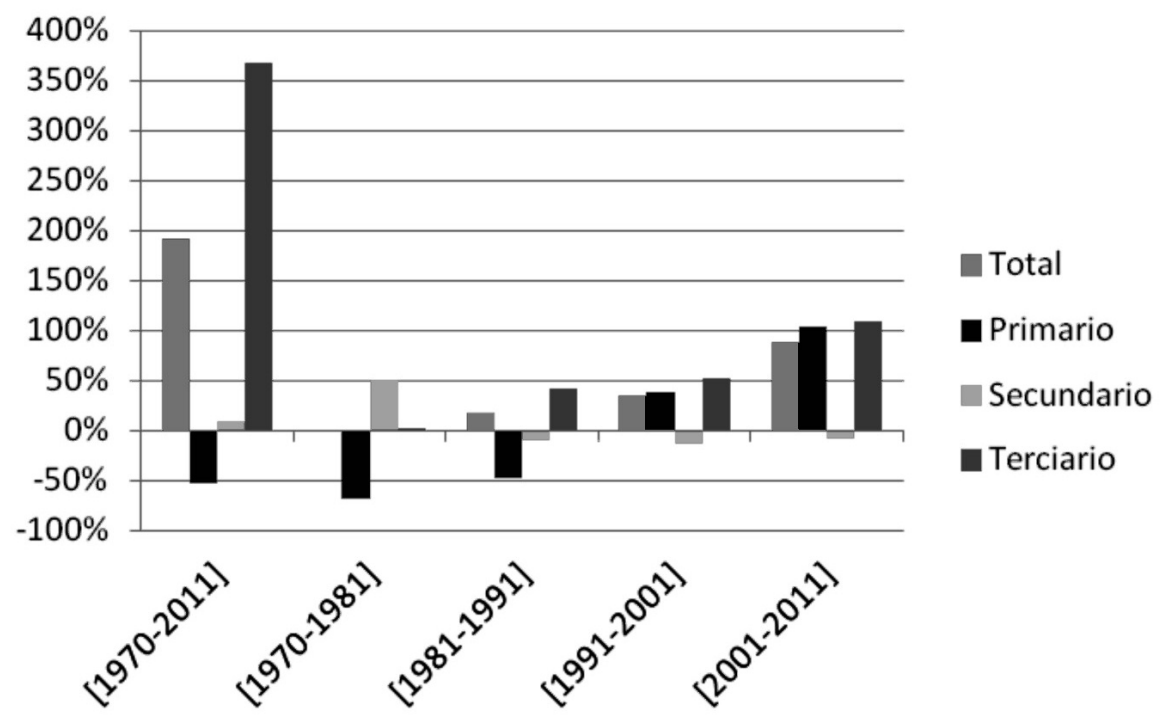

Fuente: Elaboración propia a partir de información del INE, el IEEX y la TASS. 
FIGURA 3

POBLACIÓN OCUPADA POR SECTORES ECONÓMICOS EN PAMPLONA [TASAS DE VARIACIÓN]

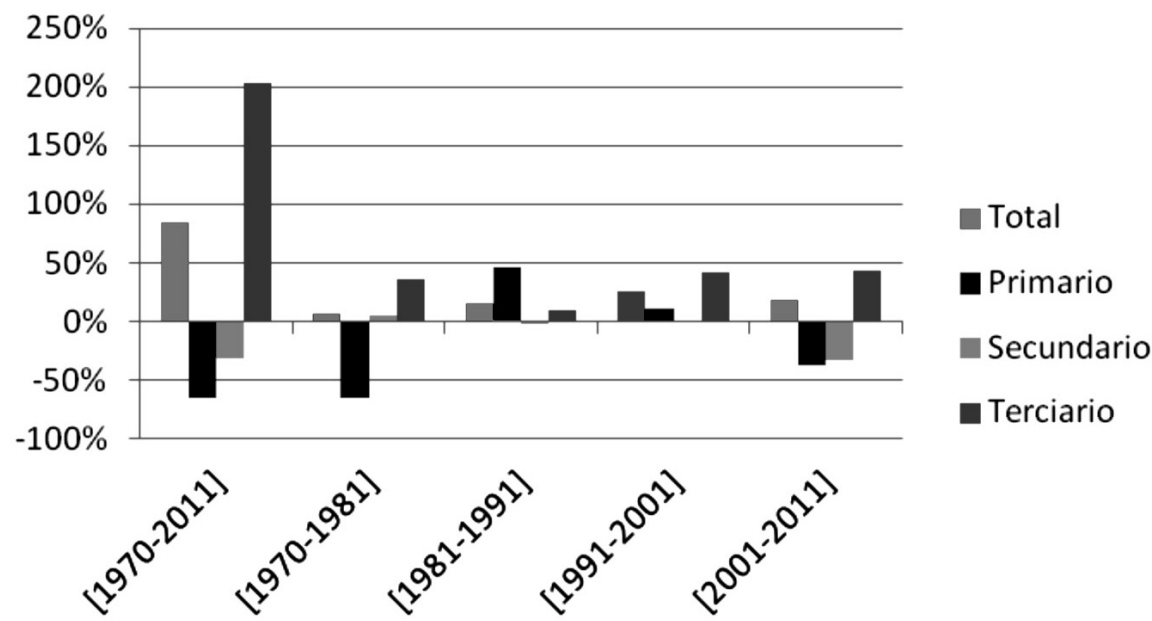

Fuente: Elaboración propia a partir de información del INE, el IEEX y la TASS.

b) En segundo lugar, el intenso crecimiento de las actividades terciarias desde 1970 hasta la actualidad. Tanto en Navarra como en Extremadura la tasa de variación es de 192 y 181\% respectivamente. Ahora, donde el crecimiento es mayor es en las dos ciudades capitales. Así, Mérida tiene una variación del 367\% (6.599 ocupados en 1970 a 30.797 en 2011), mientras que en Pamplona alcanza el 203\% (25.541 en 1970 a 77.373 en 2011). Únicamente las diferencias son notables en la tasa de variación del último decenio (20012011) que llega al 109\% en Mérida y al 43\% en Pamplona. Este hecho es sin lugar a dudas muy representativo del efecto que sobre el empleo público ha tenido la capitalidad.

c) En tercer lugar y en lo que se refiere al sector secundario, las tasas de variación ponen de manifiesto diferencias importantes entre las ciudades estudiadas y sus comunidades de referencia. En Mérida, por ejemplo, la tasa de variación desde 1970 hasta hoy se ha visto incrementada en un 8\% (2.759 en 1970 a 2.990 en 2011), mientras que en la comunidad el incremento es del 96\%. Por su parte, en Pamplona se ha producido un descenso notable (-31\%), más intenso aún si cabe en el último decenio (-33\%), mientras que en la co- 
munidad la tasa de variación del periodo es positiva (24\%); d) por último, los datos referidos al sector primario reflejan un descenso significativo en todos los casos desde 1970 hasta la actualidad (del 67\% en Extremadura, del 53\% en Mérida, del 84\% en Navarra y del 65\% en Pamplona).

\subsubsection{El peso del empleo público y otras actividades inducidas por la capitalidad}

La capitalidad autonómica de Mérida y Pamplona también ha podido suponer cambios o transformaciones en la estructura laboral, especialmente en determinados sectores. La dificultad a la hora de detectar esta cuestión estriba en la imposibilidad de obtener datos objetivos y diacrónicos. Por ello, hemos optado por diferenciar los ocupados en los diferentes momentos temporales de apartados anteriores en subsectores. Son la construcción, la administración pública y las actividades de hostelería y ocio. De todos ellos, le prestaremos especial atención a los empleados públicos puesto que es evidente que la instalación de instituciones regionales y nacionales (en el caso de Pamplona) tiene que tener su reflejo directo en el número de empleos públicos generados en ambas ciudades. Del mismo modo, entendemos que esta cuestión puede relacionarse con el crecimiento del empleo (inducido por tanto) en otros ámbitos como la construcción o determinados servicios vinculados, en mayor o menor medida, a los empleados públicos como los de hostelería y ocio ${ }^{6}$.

Ahora bien, no es menos cierto que este planteamiento puede ser rebatido. En primer lugar, el empleo generado en cualquiera de los sectores indicados, pero especialmente el referido a los empleados públicos, puede no ser cubierto forzosamente por residentes de las ciudades estudiadas. Solo el Censo de 2001 puede ayudar algo en la relación empleo-población al utilizar el criterio de la población vinculada. Y en segundo lugar, la evolución de la construcción o de los servicios de hostelería y ocio tampoco puede ser vinculada en exclusividad a la capitalidad, al menos en su totalidad. En definitiva, estas cuestiones lo que reflejan es la dificultad para llevar a cabo este tipo de análisis, más aún teniendo en cuenta las dificultades planteadas para la obtención de la información y para su interpretación.

\footnotetext{
${ }^{6}$ Es muy probable que otras actividades económicas como los servicios a las empresas y el comercio también se hayan incrementado o modificado por el efecto de la capitalidad, pero la dificultad de obtención de información al respecto y el tiempo disponible del proyecto de investigación ha hecho imposible profundizar en esta cuestión.
} 
Consideramos entonces interesante comenzar en primer lugar por dar un panorama general del empleo público en España que nos permita luego comparar los resultados obtenidos tanto en Mérida como en Pamplona. Así, el Ministerio de Política Territorial y Administración Pública, a través del Boletín Estadístico del Personal de las Administraciones Públicas, reconoce en julio de 2011 un total de 2,7 millones de empleados públicos repartidos entre la administración estatal (22\%), la regional $(50,1 \%)$, la local $(24,1 \%)$ y las universidades $(3,8 \%)$. Por otro lado, la tasa media de empleados públicos sobre población activa en España se sitúa en torno al 15,2\%, la mitad que en los países nórdicos y a un nivel similar que Estados Unidos o Italia (Gómez et al., 2009, p. 182).

¿Y qué ha ocurrido en Mérida y Pamplona? Las figuras 4 y 5 reflejan la evolución seguida por el empleo público ${ }^{7}$ en ambas ciudades y sus respectivas comunidades, desde 1970 hasta 2011. Parecen evidentes las diferencias existentes. Así, Mérida ha pasado de un 11\% de ocupados públicos en 1970 (1.320 trabajadores) a casi una tercera parte (11.402 trabajadores) en 2011 $(32,6 \%)$, convirtiéndose de este modo en la ciudad española con la proporción más elevada de empleados públicos. Sin duda, esta cuestión está directamente vinculada con la adquisición de la capitalidad por parte de la ciudad. Sin embargo, la comunidad en su conjunto también se ha caracterizado por este mismo fenómeno de crecimiento del empleo público ya que ha multiplicado por tres, en términos relativos, sus efectivos (3,7\% en 1970 y 13,9\% en 2011), y por cinco en números absolutos (10.387 empleados públicos en 1970 y 50.663 en la actualidad).

Por su parte, los gráficos indican que tanto Pamplona como su comunidad han modificado muy ligeramente el número y la proporción de trabajadores públicos desde 1970 hasta la actualidad. En la capital se ha pasado de 2.809 empleados y un 5,5\% en 1970 a 6.296 en 2011 que suponen un 6,7\% aproximadamente del total de ocupados. En la región el incremento es aún más leve y aunque ha duplicado el número de empleados públicos (pasando de 5.384 en 1970 a 9.781 en la actualidad), en términos porcentuales los valores continúan estando entre el 3 y el 4\% del total de ocupados de la región.

${ }^{7}$ En el Censo de 1970, los datos de ocupados proceden de la rúbrica 9.1 "Administración pública y defensa"; en el Censo de 1981 de la rúbrica 91 de la CNAE74 "Administración pública, Defensa nacional y Seguridad Social”; en los Censos de 1991 y 2001 de la rúbrica 27 del INE y 75 de la CNAE93 "Administraciones públicas, Defensa y Seguridad Social"; los datos de 2011 proceden de la rúbrica 84 de la CNAE09 "Administración pública y Defensa y Seguridad Social", proporcionados por la TGSS. 


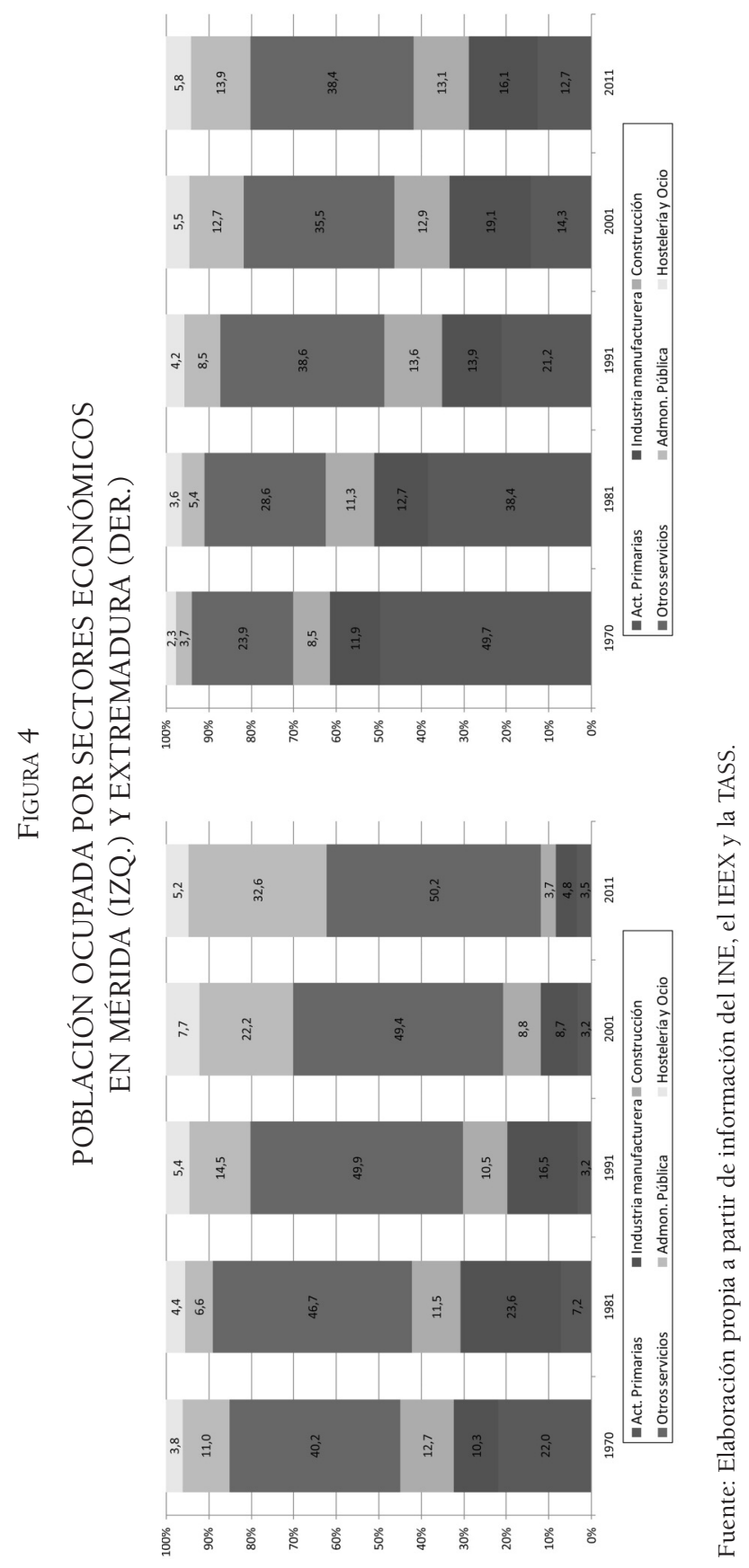

Estudios Geográficos, Vol. LXXV, 276, pp. 311-345, enero-junio 2014 ISSN: 0014-1496, eISSN: 1988-8546, doi: 10.3989/estgeogr.201408 


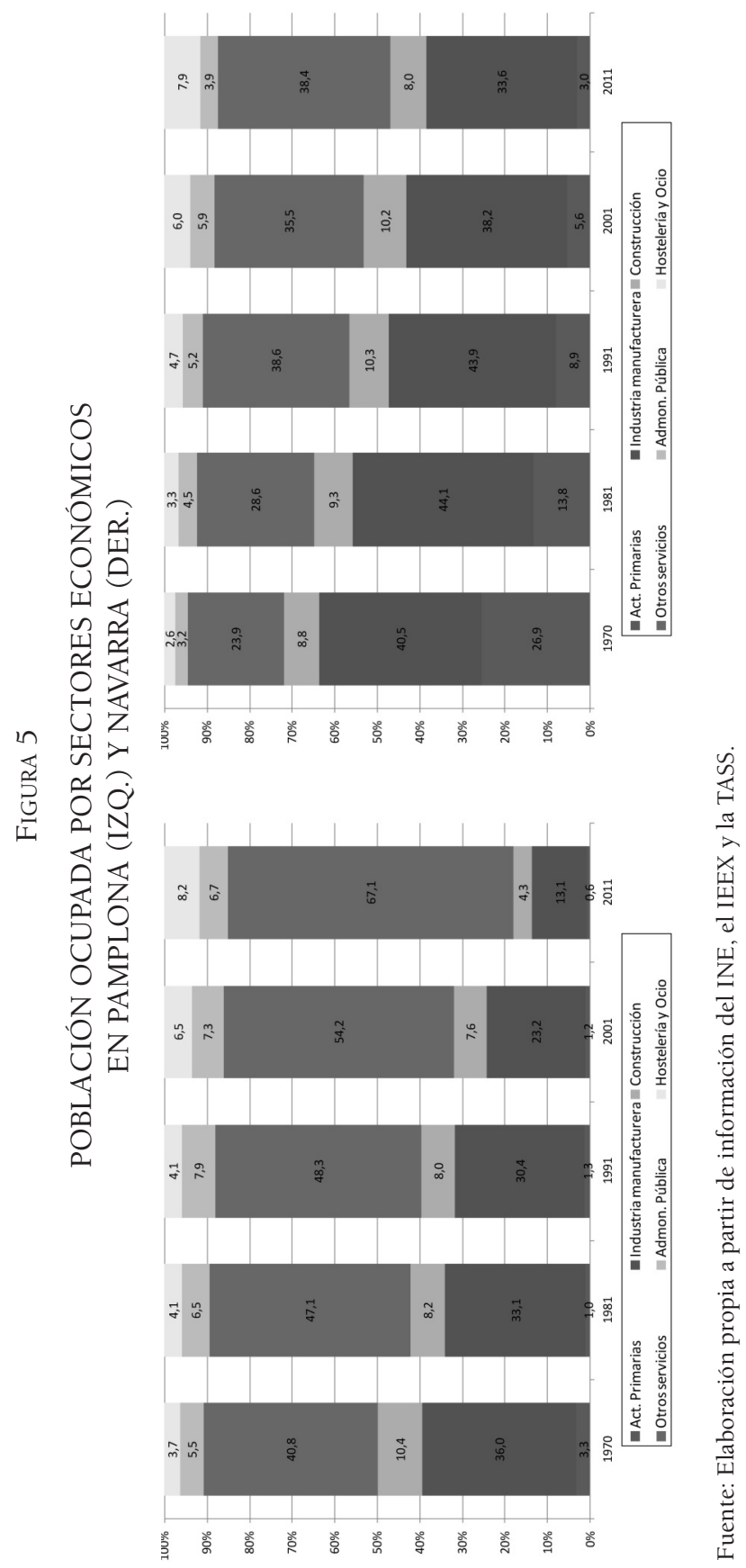

Estudios Geográficos, Vol. LXXV, 276, pp. 311-345, enero-junio 2014

ISSN: 0014-1496, eISSN: 1988-8546, doi: 10.3989/estgeogr.201408 
Por tanto, aunque el crecimiento del sector servicios es claro en las dos ciudades y en ambas comunidades desde 1970 hasta la actualidad, se plantean sustanciales desigualdades entre los dos modelos de capital regional analizados en lo que respecta a la evolución del empleo al servicio de las administraciones públicas. Mérida, que contaba con menor tradición, ha visto incrementarse de manera muy notable el empleo público y, sin embargo, Pamplona, que ya contaba con una tradición mucho más larga como capital provincial, aunque ha incrementado sus ocupados públicos, lo ha hecho de forma mucho más moderada y, de cualquier modo, de forma diferenciada de su ámbito regional de referencia. Esto es un efecto inequívoco inducido por la capitalidad.

Ahora bien, podemos concretar algo más el análisis si observamos la tabla 4 que muestra las tasas de variación por subsectores y periodos. Lo primero que llama la atención es el elevado incremento que se ha producido en los ocupados en la administración pública, tanto en las comunidades como en las ciudades analizadas. Sin embargo, este crecimiento es mucho más significativo en el caso de Mérida ( $i 764 \%$ ! en el periodo 1970-2011 frente al 124\% de Pamplona en el mismo periodo). Son además especialmente indicativos los aumentos de la ciudad pacense en los tres últimos decenios en los que, por ejemplo, se alcanza el 176\% entre 2001 y la actualidad. Aunque la dinámica es similar para Extremadura en el conjunto del periodo, por decenios los valores obtenidos son menos llamativos.

Frente a estos datos, contrasta la evolución de la comunidad foral y de la ciudad pamplonica con un crecimiento mucho más contenido en el mismo periodo que, incluso, es negativo (del orden del 30\% en ambos casos) en el último decenio. Esto viene a demostrar, sin lugar a dudas, una mayor contención en el gasto y seguramente por ende, una mayor racionalidad y eficiencia.

Tan interesante como lo anterior, resulta la comparación del volumen de los empleados al servicio de las administraciones públicas entre el conjunto de los habitantes. La tabla 5 muestra la evolución de esta ratio que como puede verse, ha aumentado en el periodo democrático de manera notable en todos los casos. Sin embargo, y nuevamente por efecto de la capitalidad, son las ciudades las que poseen una relación de empleados públicos por habitante más elevada. Así ocurre en el caso de Mérida que posee una ratio de 5,1 en la actualidad, o lo que es lo mismo, hay un empleado público por cada cinco habitantes emeritenses. Por su parte, en Pamplona el incremento ha sido más moderado hasta el 31,4 actual (un empleado público por cada 30 habitantes), situándose muy por debajo de la ratio para el conjunto del Estado (18 aproximadamente). Los valores obtenidos en las comunidades, aún siendo de los más elevados de España, son inferiores a los existentes en sus respectivas capitales (21,8 en Extremadura y 65,4 en Navarra). 


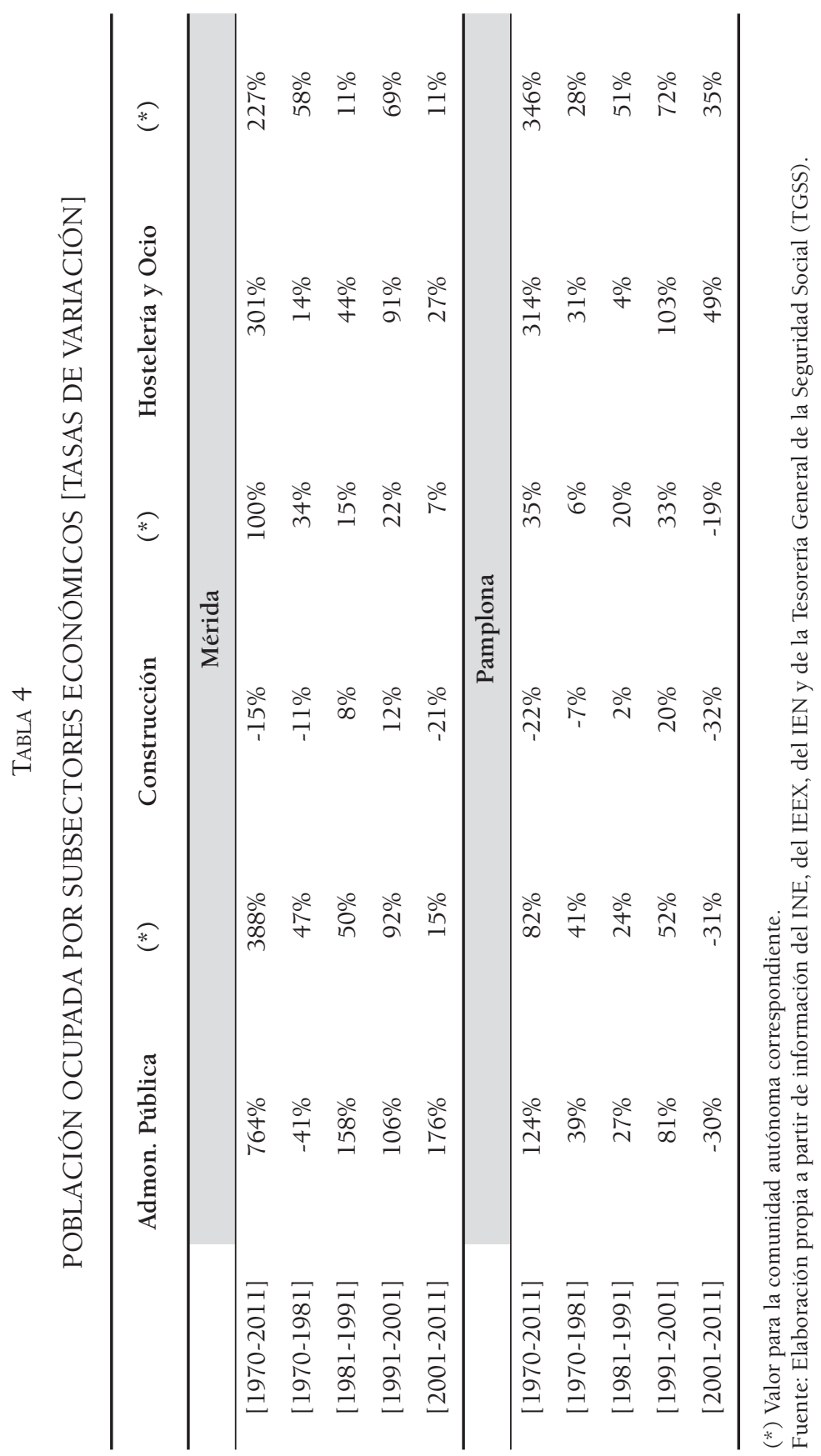

Estudios Geográficos, Vol. LXXV, 276, pp. 311-345, enero-junio 2014

ISSN: 0014-1496, eISSN: 1988-8546, doi: 10.3989/estgeogr.201408 
TABLA 5

RATIO EMPLEADOS PÚBLICOS POR HABITANTE

\begin{tabular}{ccccc}
\hline & Habitantes & $\begin{array}{c}\text { Empleados } \\
\text { públicos }\end{array}$ & Ratio & $(*)$ \\
\hline 1970 & 40.059 & 1.320 & 30,3 & 112,5 \\
1981 & 41.027 & 777 & 52,8 & 69,7 \\
1991 & 49.284 & 2.004 & 24,6 & 46,3 \\
2001 & 51.056 & 4.133 & 12,4 & 24,0 \\
2011 & 57.797 & 11.402 & 5,1 & 21,8 \\
\hline 1970 & 147.168 & 2.809 & 52,4 & 86,6 \\
1981 & 177.906 & 3.905 & 45,6 & 67,1 \\
1991 & 180.372 & 4.967 & 36,3 & 55,2 \\
2001 & 186.245 & 8.980 & 20,7 & 38,9 \\
2011 & 197.932 & 6.296 & 31,4 & 65,4 \\
\hline
\end{tabular}

(*) Valor para la comunidad autónoma correspondiente.

Fuente: Elaboración propia a partir de información del INE, del IEEX, del IEN y de la TASS.

Los datos expuestos son suficientemente ilustrativos de las diferencias existentes entre ambas ciudades en lo que se refiere a la evolución del empleo público. Ahora bien, es necesario hacer un inciso en un aspecto en el que la divergencia podría ser más ilustrativa. Para ello, se ha recurrido al dato de la población vinculada ${ }^{8}$ que desafortunadamente sólo recoge el Censo de Población y Viviendas de 2001. Así, en Mérida hay una cantidad flotante (que trabaja pero que no reside) de 5.797 efectivos (261 de Almendralejo; 1.102 de Badajoz; 183 de Don Benito; 110 de Villanueva de la Serena y 4.141 de municipios menores), lo que supone aproximadamente una tercera parte del total de ocupados (18.618). Por otro lado, Pamplona, según esa misma fuente,

${ }^{8}$ Según la definición del INE: Conjunto de personas censables (es decir, con residencia habitual en España) que tienen algún tipo de vinculación habitual con el municipio ya sea porque residen allí, porque trabajan o estudian allí o porque, no siendo su residencia habitual, suelen pasar allí ciertos periodos de tiempo (veraneos, puentes, fines de semana). 
tiene 29.743 efectivos (272 de Tudela; 4.630 de Barasain y 24.841 de municipios menores) que no tienen como residencia habitual la capital aunque sí tienen vinculación laboral con la misma. Esto supone alrededor de un $40 \%$ de la población ocupada en ese mismo año (79.635).

Aunque desde algunas instancias se ha criticado el hecho de que Mérida tenga un número cuantioso de empleados públicos que no residen en la ciudad, lo cierto es que el modelo suburbano navarro resulta más favorable para los desplazamientos cotidianos residencia-trabajo, lo que explicaría el porqué del volumen de población vinculada más elevado. Esta cuestión además pone de manifiesto la importancia de las capitales autonómicas, puesto que ni Badajoz (que tiene un 15\%), ni siquiera el conjunto de Extremadura (con un 10\%), tienen valores de población vinculada tan elevados como Mérida. Del mismo modo, en el conjunto de la comunidad navarra, la población flotante solo supone el $10 \%$ de los ocupados. Tampoco se puede perder de vista el hecho de que las cifras no diferencian el sector económico de los trabajadores vinculados y que, por tanto, no puede extrapolarse únicamente para el estudio de los empleados públicos.

¿Y qué ha ocurrido con los restantes sectores económicos? Pues bien, la evolución de este empleo inducido, que también aparece en las tablas y figuras anteriores, presenta igualmente similitudes y diferencias tanto a nivel regional como local. Así, resulta paradójico el descenso en el número y la proporción de efectivos de la construcción ${ }^{9}$, tanto en Mérida como en Pamplona, desde 1970 hasta la actualidad. En la primera ciudad, los ocupados han pasado de 1.523 en 1970 (12,7\% del total) a 1.291 en la actualidad (3,7\%). En el segundo caso, los trabajadores de la construcción eran 5.294 en 1970 $(10,4 \%)$ y son 4.103 en la actualidad (lo que supone el 4,3\% del total de ocupados). Las tasas de variación también lo reflejan con un descenso del 15 y del $22 \%$ respectivamente entre el inicio y el final del periodo de estudio, siendo en ambos casos especialmente acusado en el decenio 2001-2011 en el que Mérida ha perdido un $21 \%$ y Pamplona casi una tercera parte (32\%). Esto es sin duda un reflejo de la crisis económica de los últimos años del periodo y del parón constructivo. Paradójicamente, en ese mismo periodo, este sector ha aumentado en términos absolutos y porcentuales en Extremadura y se ha reducido pero en menor medida en Navarra.

\footnotetext{
${ }^{9}$ En el Censo de 1970, los datos de ocupados proceden de la rúbrica 5; en el Censo de 1981 de la rúbrica 50 de la CNAE74; en los Censos de 1991 y 2001 de la rúbrica 17 del INE y 45 de la CNAE93. En todos los casos el epígrafe es «Construcción»; los datos de 2011 proceden de las rúbricas 41 a 43 de la CNAE09, proporcionados por la TGSS.
} 
Por su parte, los ocupados en otros de esos sectores, que han podido tener cierto efecto arrastre por la capitalidad y el empleo público, como son los de hostelería y ocio ${ }^{10}$, han tenido un comportamiento dispar en ambas ciudades. Así, en Pamplona el crecimiento ha sido notable tanto en términos absolutos como porcentuales desde 1970 (1.871 ocupados que suponían un 3,7\%) hasta la actualidad (7.737 trabajadores y un 8,2\%). Mientras, en Mérida la evolución fue positiva desde 1970 (456 ocupados y un 3,8\%) hasta 2001 (1.438 y un $7,7 \%$ ), aunque los datos de 2011 reflejan un descenso difícilmente explicable que sitúa el empleo en estos sectores en 1.827 trabajadores que suponen un $5,2 \%$ del total de ocupados. No obstante, estos datos son muy diferentes si examinamos las tasas de variación. Así, por ejemplo, en Pamplona el porcentaje del periodo $1970-2011$ es del 314\%, siendo todavía más elevado el de la comunidad con un 346\%. Por su parte, en Extremadura la tasa de variación de este mismo sector ha sido del 227\%, siendo la de Mérida del 301\%. En cualquier caso se trata de cifras muy elevadas que no podemos achacar única y exclusivamente al efecto de la capitalidad puesto que los incrementos han sido también notables a escala autonómica.

\section{LA CAPITALIDAD Y LAS TRANSFORMACIONES RESIDENCIALES EN MÉRIDA Y PAMPLONA}

La capitalidad en ambas ciudades, además de haber modificado en mayor o menor medida la dinámica demográfica y el empleo, también ha podido tener incidencia en la evolución residencial. Sin embargo, es necesario tener en cuenta una serie de precisiones previas al análisis. Por un lado, no hay que perder de vista el hecho de que hablamos de modelos urbanos diferenciados en ambas ciudades. Ya hemos planteado anteriormente como el crecimiento suburbano es una de las características predominantes en Pamplona desde hace décadas, frente al modelo más concentrado de Mérida. En la primera, el alto coste de las viviendas urbanas o su antigüedad ha provocado un efecto de desplazamiento de la población hacia los municipios limítrofes, extendién-

${ }^{10}$ En el Censo de 1970, los datos de ocupados proceden de las rúbricas 6.3 "Restaurantes y hoteles" y 9.4 "Servicios culturales y de diversión y esparcimiento"; en el Censo de 1981 de las rúbricas 65, 66 y 96 de la CNAE74 "Restaurantes y cafés; Hostelería"; Servicios recreativos y culturales"; en el Censo de 1991 de la rúbrica 21 del INE y 55 de la CNAE93 "Hoteles, restaurantes, bares y similares"; en el Censo de 2001 de las rúbricas 55 y 92 de la CNAE93 "Hostelería"; "Actividades, recreativas, culturales y deportivas"; los datos de 2011 proceden de las rúbricas 55, 56 y 93 de la CNAE09 "Servicios de alojamiento; Servicios de comidas y bebidas; Actividades deportivas, recreativas y de ocio", proporcionados por la TGSS. 
dose así por toda la cuenca que la rodea mediante pequeños pueblos de servicios, grandes urbanizaciones de viviendas unifamiliares, chalets adosados y grandes zonas recreativas o grandes superficies comerciales (Alli, 2001, p. 54). Todo ello influye, sin lugar a dudas, en las transformaciones residenciales de estos años. En el caso de la capital extremeña, aunque el rasgo fundamental es el anterior, las tendencias apuntan hacia el reforzamiento de los ejes OesteEste (Badajoz-Mérida) y Norte-Sur (Mérida-Zafra), esto es, en torno a la Vega Baja del Guadiana y la Tierra de Barros (Campesino, 2003, p. 46).

Además, las desigualdades económicas existentes a nivel regional y local también son un elemento distorsionador de la vivienda, tanto para la oferta privada como para la pública. Hay que tener en cuenta que las estadísticas no diferencian entre ambos sectores y que, por tanto, cuando nos referimos a la vivienda la estamos considerando de manera conjunta. Esto se relaciona con el hecho de que ninguna de las dos instituciones públicas implicadas en la provisión de vivienda (Navarra de Suelo y Vivienda, S.A. y Gestión de Infraestructuras, Suelo y Viviendas de Extremadura, S.A.) ha planteado programas específicos para fijar empleados públicos o líneas de actuación prioritarias para este colectivo. Al menos no con la entidad y duración suficiente como para ser un elemento a considerar en alguna de las dos ciudades estudiadas. Únicamente hemos encontrado algún ejemplo de promoción de viviendas destinadas a alojar a funcionarios (por cuenta de la administración nacional y regional), construidas en los años ochenta, en el Barrio de Bellavista de Mérida e indirectamente, en promociones de la misma ciudad pertenecientes al Programa Especial 60.000 como Mérida III Milenio, que es precisamente una de las promociones de vivienda protegida que se localiza en un barrio de reciente creación en las proximidades de seis consejerías de la Junta de Extremadura.

Entre las cuestiones más destacables están los notables crecimientos de los valores absolutos en el número de viviendas. En Extremadura el incremento, aun siendo notable (más de 240.000 viviendas construidas desde 1970 hasta hoy), no tiene su correlato con la dinámica demográfica y además no es tan elevado como en Mérida. Por ejemplo, con anterioridad al Estatuto de Autonomía existían en 1970 y 1981 un total de 11.286 y 15.319 residencias, respectivamente. Sin embargo, treinta años después, y en línea con la propia dinámica demográfica (figura 6) tenemos 25.836 viviendas para unos 58.000 residentes. En estos años se han ido consolidando bajo diferentes planes las zonas edificadas y se han desarrollado bajo la fórmula de Programas de Actuación Urbanística y Plan Parcial algunos sectores como los de El Torillo (15 hectáreas y 544 viviendas), Los Bodegones (26,1 hectáreas y 948 viviendas) o el Sector N-4 (14,4 y 703 viviendas). 


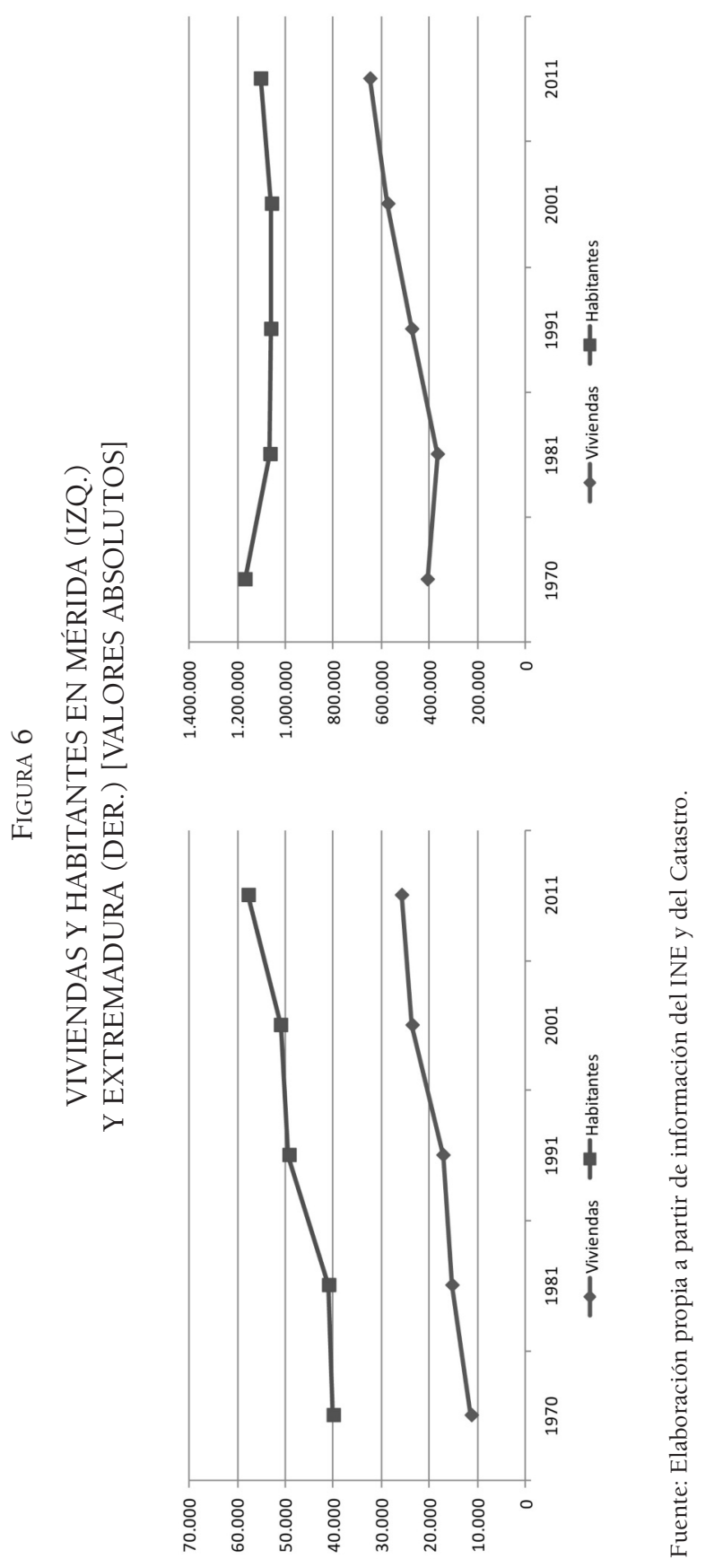

Estudios Geográficos, Vol. LXXV, 276, pp. 311-345, enero-junio 2014 ISSN: 0014-1496, eISSN: 1988-8546, doi: 10.3989/estgeogr.201408 
El nuevo siglo ha visto crecer la ciudad en todas las direcciones con nuevos suelos urbanizables. El nuevo plan preveía la extensión hacia el norte por la carretera de Cáceres en la zona de Las Abadías (2.764 viviendas en 69 hectáreas), hacia el oeste 69 hectáreas y 2.610 viviendas, hacia el suroeste, en la margen izquierda del río Guadiana, 65 hectáreas y 2.750 viviendas y, finalmente, hacia el sureste, por la otra margen, 1.885 viviendas, previa supresión de la vía del ferrocarril (Barbudo, 2006, p. 287).

Coetáneos en el tiempo son también de interés las promociones de vivienda incluidas en el Programa Especial 60.000 de Villaemérita (210 viviendas), La Calzada (584 viviendas) o Mérida III Milenio (446 viviendas). Esta última se localizaría en las proximidades de un entorno problemático como es la Barriada de la Paz. Estaría vinculada a una operación urbana de magnitud considerable al ser considerado un proyecto de interés regional que ha dado lugar a la construcción de este barrio y varias consejerías e instituciones públicas.

A diferencia del caso anterior, tanto en Navarra como en Pamplona (figura 7) se observa una clara vinculación entre el incremento del número de viviendas y el de la población. En ambos casos se han multiplicado por más de dos veces ambas variables. Por ejemplo, en Pamplona había 38.000 y 56.000 viviendas en 1970 y 1981, respectivamente, que han aumentado hasta las 88.000 en la actualidad para unos 200.000 residentes. Son el resultado de un modelo de desarrollo urbano navarro que como vimos está caracterizado por la periurbanización, y ha propiciado que obviamente Pamplona en su crecimiento haya ido absorbiendo alguno de los municipios exteriores (Mendillorri $^{11}$ o Echavacoiz ${ }^{12}$ por ejemplo), o bien los haya ido convirtiendo en zonas de residencia totalmente vinculada a la capital (Alli, 2001, p. 50).

Del mismo modo, durante las últimas décadas el planeamiento ha ido ordenando la vitalidad demográfica de Pamplona y ha favorecido la creación de nuevos barrios (o la renovación de áreas consolidadas ${ }^{13}$ ) como Mendebaldea o la parte nueva de San Juan al oeste y Azpilagaña, al sur de la ciudad y limitando con los barrios de Iturrama y La Milagrosa.

${ }^{11}$ En 1995 quedó incorporado a la ciudad el barrio de Mendillorri, uno de los proyectos más ambiciosos en términos urbanísticos de los noventa en España, que nació como espacio residencial con una importante proporción de viviendas protegidas al este de la ciudad.

12 Integrado en 1953 pero con zonas residenciales más modernas como Echavacoiz Norte, situado junto a Barañáin.

${ }^{13}$ En la obra de Azanza (2010) se puede encontrar un interesante y exhaustivo repaso de las transformaciones urbanas acontecidas en los últimos años en los terrenos del Primer Ensanche de la ciudad. 


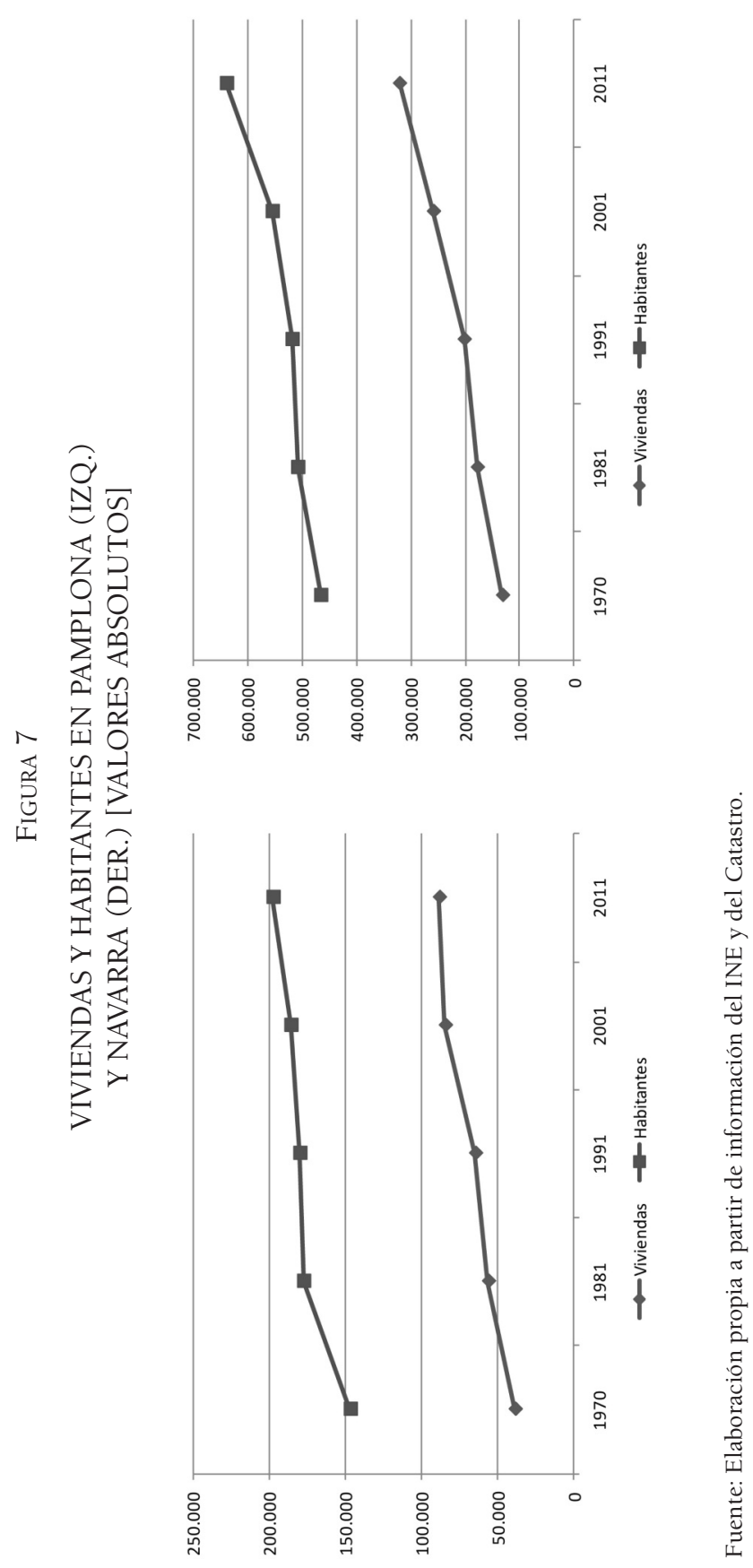

Estudios Geográficos, Vol. LXXV, 276, pp. 311-345, enero-junio 2014 ISSN: 0014-1496, eISSN: 1988-8546, doi: 10.3989/estgeogr.201408 
En la actualidad la expansión de la trama urbana continúa con urbanizaciones de reciente creación en Rochapea (que cuenta con nuevas urbanizaciones como Rochapea Norte aunque se trate de uno de los barrios más antiguos de Pamplona), San Jorge (barrio de notable antigüedad al noroeste de la ciudad que ha sufrido en las últimas décadas un proceso notable de sustitución de la edificación en algunas de sus zonas), Buztintxuri (un barrio dormitorio al norte de la ciudad que comenzó a levantarse en 2003), Ezcaba (situada al nordeste de la ciudad empezaría a desarrollarse en 2006) y Lezcairu-Arrosadía, un nuevo barrio en construcción al sur del Segundo Ensanche.

Las tasas de variación para ambas ciudades y comunidades (figuras 8 y 9) presentan igualmente algunos rasgos característicos. Así, aunque los valores son elevados en las dos regiones para el periodo 1970-2011, en Navarra el incremento es mucho mayor (144\% frente al 58\% de Extremadura). Sin embargo, cuando analizamos las tasas de las ciudades podemos apreciar que ambas coinciden para el periodo 1970-2011 y son además elevadas (129\%). El

FIGURA 8

VIVIENDAS POR PERIODOS EN MÉRIDA Y EXTREMADURA [TASAS DE VARIACIÓN]

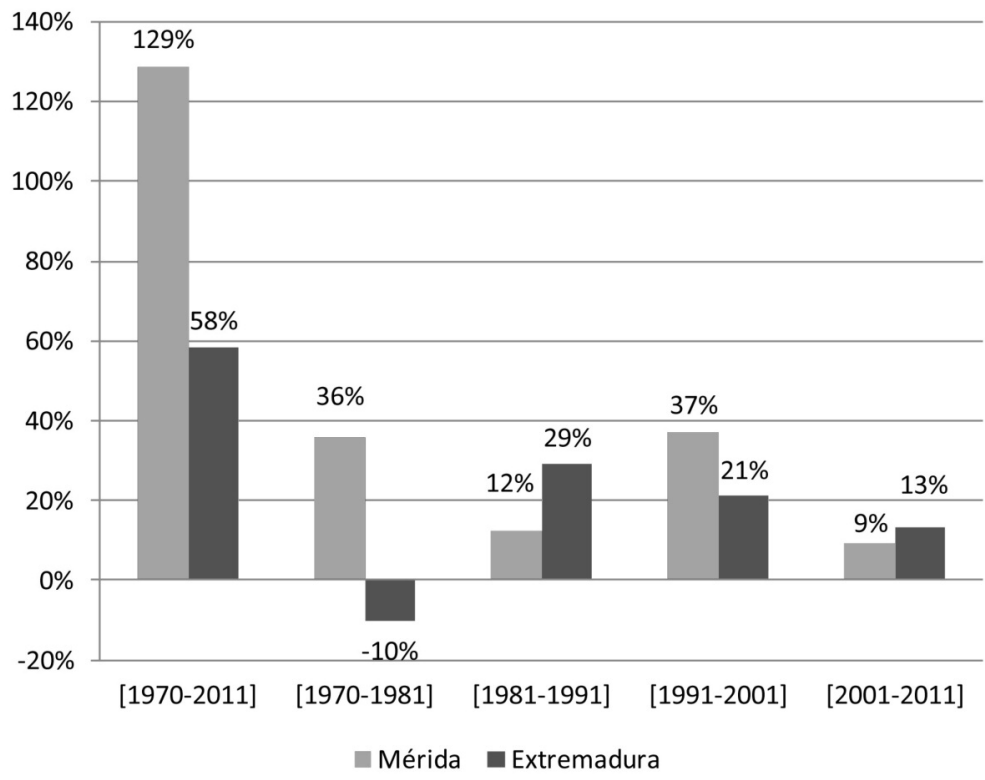

Fuente: Elaboración propia a partir de información del INE y del Catastro.

Estudios Geográficos, Vol. LXXV, 276, pp. 311-345, enero-junio 2014

ISSN: 0014-1496, eISSN: 1988-8546, doi: 10.3989/estgeogr.201408 
FIGURA 9

VIVIENDAS POR PERIODOS EN PAMPLONA Y NAVARRA

[TASAS DE VARIACIÓN]

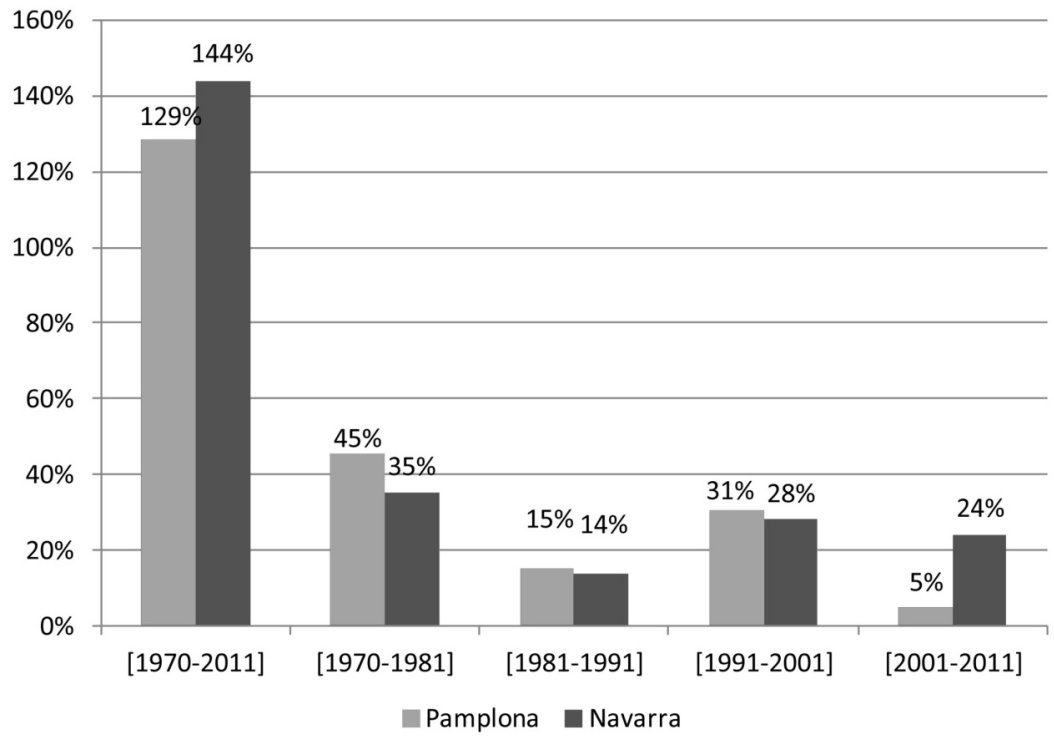

Fuente: Elaboración propia a partir de información del INE y del Catastro.

resto de valores muestra una evolución similar tanto para Mérida como para Pamplona, siendo las más altas las correspondientes al periodo 1991-2001 con más de un 30\% en ambos casos, y las más reducidas las del último decenio que no alcanzan el $10 \%$ en ninguna de ellas.

La tabla 6 muestra la ratio viviendas por habitante para las dos ciudades y sus correspondientes comunidades. Como se puede apreciar, las diferencias entre las primeras son prácticamente inexistentes. De hecho, los valores en todos los años estudiados son casi idénticos, aumentando a medida que nos acercamos a la actualidad. En 1970, la ratio era de aproximadamente una vivienda por cada tres habitantes ( 0,28 en Mérida y 0,26 en Pamplona), mientras que en 2011 esa proporción ha aumentado hasta casi una vivienda por cada dos habitantes, tanto en Mérida $(0,45)$ como en Pamplona $(0,46)$, teniendo además un valor similar al obtenido diez años antes. Esta relación también se ha incrementado con el paso de tiempo en el caso de las regiones, 


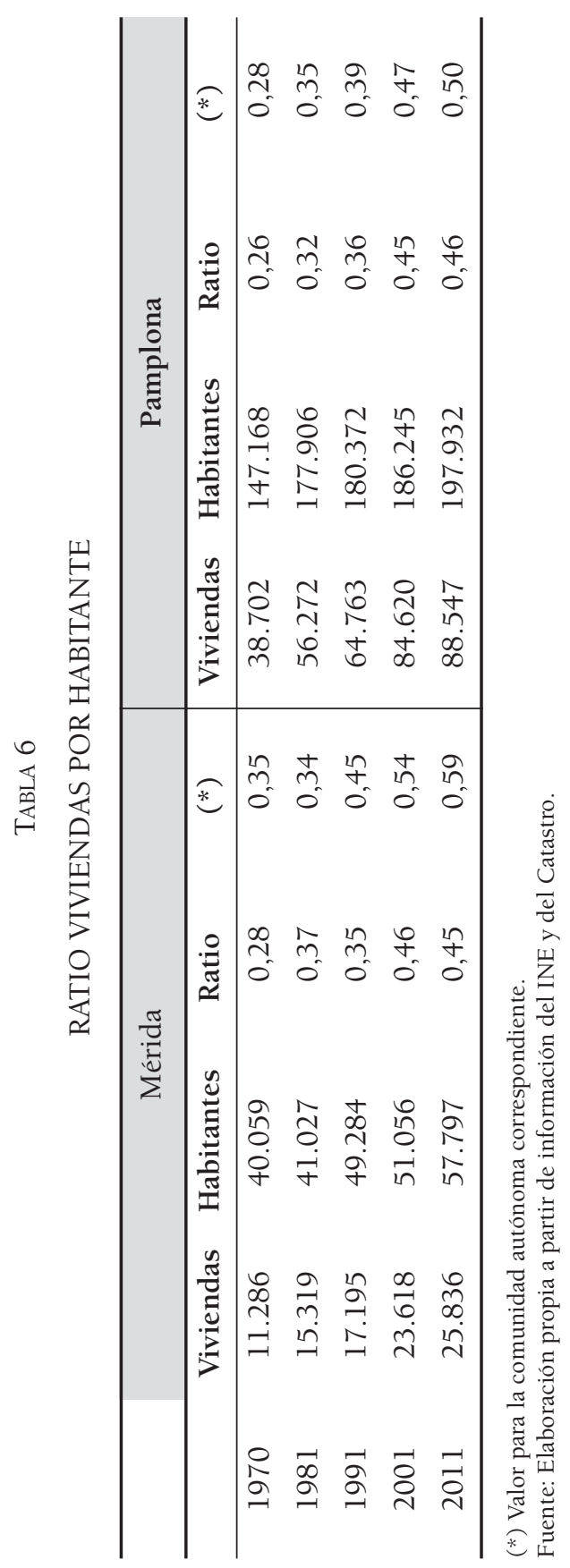

Estudios Geográficos, Vol. LXXV, 276, pp. 311-345, enero-junio 2014

ISSN: 0014-1496, eISSN: 1988-8546, doi: 10.3989/estgeogr.201408 
presentando además valores más elevados (próximos a 0,30 en 1970 y por encima del 0,50 en 2011). De hecho, en Extremadura en 2011 la ratio es de más de una vivienda por cada dos habitantes.

Estos datos tampoco son especialmente significativos para establecer valoraciones definitivas en lo que respecta a la posible repercusión de la capitalidad en el mercado de la vivienda. De hecho, la ratio en ambas ciudades está por debajo en la actualidad de las que se obtienen en comparación con la provincia (Badajoz tiene 0,54), la Comunidad Autónoma (como ya hemos visto) y el conjunto del Estado $(0,54)$.

\section{CONCLUSIONES Y PERSPECTIVAS DE FUtURO}

Esta investigación ha puesto de manifiesto las dificultades, trabas y obstáculos que existen en este país para la obtención de información relativa a la estructura socio-profesional y a la vivienda. Existen fuentes diversas y heterogéneas, que, en ocasiones, simplemente duplican la información estadística, como ocurre con el INE y los institutos de estadística regionales. Además, es difícil conseguir información histórica. Cuando existen dichos datos, la ausencia de continuidad es la tónica dominante. Esto dificulta enormemente la comparabilidad de las cifras y por ende, la verosimilitud de los resultados de cualquier investigación.

Con todo, la interpretación de la información obtenida permite verificar que el impacto de la capitalidad no ha sido notable en las ciudades analizadas, tanto en términos demográficos, como laborales y residenciales, sobre todo si las comparamos entre ellas y con su estructura espacial autonómica correspondiente.

En lo que respecta a la dinámica demográfica de ambas ciudades desde que son capitales autonómicas, parece evidenciarse un crecimiento sostenido de su población, tanto en valores absolutos (16.000 habitantes en Mérida y 20.000 en Pamplona aproximadamente) como en las tasas de variación por periodos. Esto resulta más evidente aún si cabe en el caso de Mérida que ha aglutinado en este tiempo una tercera parte del crecimiento total regional, mientras que en el conjunto de Extremadura la tasa de variación ha sido negativa (en Extremadura viven hoy 60.000 habitantes menos que en 1970).

El resto de indicadores demográficos analizados no permite extraer conclusiones definitivas con su vinculación a la capitalidad. Sencillamente están en línea con el proceso de transición demográfica acontecida en los países desarrollados en las últimas décadas, tanto a nivel regional como local. 
Por otro lado, el análisis de la estructura socio-profesional muestra una mayor intensidad del proceso de terciarización de la economía de ambas ciudades si lo comparamos con el de sus respectivas regiones. Tanto una como otra superan el $80 \%$ de su población ocupada en el sector terciario, muy por encima de los valores obtenidos en Extremadura (58\%) y Navarra (63\%). A eso habría que unirle el hecho de que en Mérida la tasa de variación del periodo es de un 367\% lo que duplica el valor regional. ¿Es esto un efecto de la capitalidad? Sí, pero también de su propio carácter urbano.

El crecimiento del empleo público como consecuencia de su designación como capitales autonómicas es nuevamente más evidente en el caso de Mérida que en el de Pamplona. La capitalidad le ha supuesto a la ciudad emeritense un incremento notable de los trabajadores públicos, tanto en valores absolutos (los ha multiplicado por 10 desde 1970) como porcentuales (los ha multiplicado por 3 desde ese mismo año). Eso supone que la tasa de variación del periodo 1970-2011 es de un increíble 764\%. En 2011 los empleados públicos suponen el 32,6\% de los ocupados totales, situándose muy por encima de otros núcleos urbanos como Badajoz y de la propia comunidad autónoma. De hecho, la ratio empleado público por habitante es una de las más elevadas del conjunto nacional. La otra cara de la moneda sería para Pamplona que aunque ha visto incrementado cuantitativamente el número de empleados públicos, el peso respecto al conjunto de ocupados solo ha aumentado ligeramente desde 1970 hasta la actualidad. Se trata por tanto de dos modelos claramente diferenciados. El primero se correspondería con una localidad histórica pero que recibe la capitalidad autonómica de forma «inesperada», mientras que Pamplona continúa una larga tradición de capitalidad.

El análisis del impacto laboral de las nuevas capitales autonómicas también se ha realizado a partir de indicadores como la población vinculada y el empleo inducido en sectores como la construcción, la hostelería o las actividades de ocio. En ningún caso, su interpretación es lo suficientemente rotunda como para afirmar que su evolución está única y exclusivamente vinculada con el hecho de ser capital regional. Es cierto que hay más habitantes vinculados en Mérida y Pamplona que en sus respectivas regiones. También lo es que se ha incrementado de manera notable el número de ocupados en la construcción (hasta el 2001) y en hostelería y ocio. Entonces, ¿la capitalidad ha influido en el crecimiento de estos sectores por su vinculación fundamental con los empleados públicos y con las instituciones presentes en cada una de las ciudades? A la vista de los resultados obtenidos creemos que no. Cualquiera de ellos puede vincularse a otras cuestiones ajenas al objeto de estudio de esta investigación. Por ejemplo, el hecho de que Mérida fuera declarada Patrimonio de la 
Humanidad en 1993 ha supuesto la visita de miles de turistas anuales o el cambio en las infraestructuras destinadas al servicio público lo que en definitiva, también tiene mucho que ver con el crecimiento del empleo en estos sectores.

Por último, en lo que respecta a la dinámica residencial, podríamos afirmar que el impacto de la capitalidad, caso de existir, es más notorio en el caso de Mérida que en el de Pamplona. En la primera ciudad existe una correspondencia directa entre el incremento del número de viviendas y el de su población que es, además, mucho más intenso que en su región. Sin embargo, aunque se ha incrementado paulatinamente la ratio en relación a los habitantes, los valores obtenidos son inferiores a los registrados en otras ciudades, regiones o incluso para el conjunto del Estado. Esta cuestión pone en entredicho el verdadero impacto de la capitalidad en esta cuestión.

En definitiva, esta aportación ha servido para evidenciar que el modelo autonómico no se puede tratar de la misma forma en todas las capitales, ya que existen factores físicos, históricos o demográficos que obstaculizan su comparación. Las diferencias existentes entre Mérida y Pamplona ya eran evidentes con anterioridad a la capitalidad y lo seguirán siendo en los años venideros. La racionalización del gasto en las comunidades autónomas, tan necesaria para superar la crisis actual, afectará necesariamente más a aquellas regiones que como Extremadura destinan más de una tercera parte de su presupuesto a los costes de personal.

Fecha de recepción: 04/06/2013.

Fecha de aceptación: 07/10/2013.

\section{REFERENCIAS BIBLIOGRÁFICAS Y OTRAS LECTURAS}

Alli, J. (2001): "El dilema de Pamplona: reurbanizar su caso urbano o urbanizar su cuenca". Azkoaga, 8, pp. 49-78.

Azanza, J. (2010): "De ensanche militar a city de Pamplona: arquitectura y urbanismo para una nueva imagen de la ciudad". Príncipe de Viana, 249, pp. 27-74.

Barbudo, F. (2006): Mérida, su desarrollo urbanístico desde los planos de alineaciones al Plan Especial del conjunto histórico-arqueológico, Mérida, Asamblea de Extremadura.

Bosch, N.; Espasa, M. y Montolio, D. (2011): "Estimación de los costes de centralidad y capitalidad de las grandes ciudades españolas", en XIII Encuentro de Economía Pública, Málaga [s.l. s.n.].

Campesino, A. (2003): "La ordenación territorial de la Extremadura del siglo XXI". Territoris, 4, pp. 43-60. 
Capel, H. (2009): "Las pequeñas ciudades en la urbanización generalizada y ante la crisis global". Investigaciones Geográficas, 70, pp. 7-32.

Caravaca, I. y González, G. (2009): "Las redes de colaboración como base del desarrollo territorial". Scripta Nova. Revista Electrónica de Geografía y Ciencias Sociales, XII/289, Barcelona, Universidad de Barcelona. (http://www.ub.es/geocrit/sn/sn289.htm). Consultada en marzo de 2014.

Caravaca, I.; González, G. y Mendoza, A. (2007): "Indicadores de dinamismo, innovación y desarrollo: su aplicación en ciudades pequeñas y medias de Andalucía". Boletín de la Asociación de Geógrafos Españoles, 43, pp. 131-154.

Ganau, J. y Vilagrasa, J. (2003): "Ciudades medias en España: posición en la red urbana y procesos urbanos recientes", en Capel, H. (coord.): Ciudades, arquitectura y espacio urbano. Almería, Caja Rural Intermediterránea, pp. 37-73.

Gómez, J. S.; Sánchez, J. y Rivas, C. (2009): "La Geografía del empleo público en España: especial consideración del empleo público autonómico". Revista de Estudios Regionales, vol. extraordinario, pp. 181-208.

Méndez, R. (2009): "Conocimiento e innovación para el desarrollo de ciudades intermedias", en Junta de Andalucía (ed.): Ciudades, culturas y fronteras en un mundo en cambio. Sevilla, Consejería de Obras Públicas y Transportes, pp. 20-43.

Méndez, R.; Sánchez Moral, S.; Abad, L. y García Balestena, I. (2008): "Dinámicas industriales, innovación y sistema urbano en España: trayectorias de las ciudades intermedias". Boletín de la Asociación de Geógrafos Españoles, 46, pp. 227-260.

Méndez, R.; Michelini, J. y Romero, P. (2006): "Redes socio-institucionales e innovaciones para el desarrollo de las ciudades intermedias". Ciudad y Territorio. Estudios Territoriales, XXXVIII/148, pp. 377-395.

Serrano, J. Ma . (1987): "Las capitales político-administrativas de las Comunidades Autónomas españolas. Un sistema de ciudades en proceso de consolidación”. Papeles de Geografía, 13, pp. 21-49.

Serrano, J. Ma . (2002): "Las capitales político-administrativas de las Comunidades Autónomas españolas: su significación dentro de los subsistemas urbanos regionales". Papeles de Geografía, 36, pp. 147-170.

\section{RESUMEN}

La capitalidad política regional que asumen algunas ciudades españolas a partir de la transición democrática, ha supuesto numerosas transformaciones en ellas. El objetivo de este artículo es mostrar en qué han consistido estos cambios desde una triple perspectiva analítica: de la dinámica demográfica; de la evolución de la población activa; y, finalmente, de las transformaciones residenciales. Para ello, y en base a una metodología de estudios de caso, se han seleccionado dos ejemplos representativos de ciudades medias. Pamplona, como capital autonómica de régimen foral y Mérida, como capital autonómica implantada en ciudades no capitales regionales. Aun asumiendo las notables diferencias entre ambas ciudades, su nexo de unión estriba en el hecho de que 
ambas se constituyen como centros vitales para la gestión política y administrativa de sus respectivas regiones, aglutinando el gobierno regional, ejecutivo y legislativo.

Palabras Clave: Mérida; Pamplona; capitalidad; dinámica demográfica; empleo; vivienda.

\begin{abstract}
The regional political capital assumed by some Spanish cities due to the transition to democracy has transformed these cities in many ways. The aim of this paper is to show that these changes have involved a triple analytical perspective: population dynamics, the evolution of the labor force, and finally residential transformations. Using a methodology based on case studies, we have selected two representative examples of medium-sized cities. Pamplona as a regional capital of a statutory system and Merida as an autonomic capital city implemented in non regional capitals cities. Even assuming the notable differences between the two cities, both are vital centers for political and administrative affairs of their respective regions, bringing together regional government, executive and legislative.
\end{abstract}

KEY WORDS: Mérida; Pamplona; capital city; population dynamics; employment; housing.

\title{
RÉSUMÉ
}

Aprés la transition démocratique, certaines villes de l'Espagne assument un statut de capitale politique régionale ce qui a entraîné des nombreuses transformations en leur sein. Le but de cet article est de montrer les changements apportés d'un triple point de vue analytique: la dynamique démographique; l'évolution de la population active; et enfin les transformations résidentielles. Pour faire cela, et sur la base d'une méthodologie pour les études de cas, deux exemples représentatifs des villes de taille moyenne ont été sélectionnés. Pamplona, la capitale régionale du régime foral et Merida capitale autonome établie dans une ville qui n'est pas une capitale de la province. Même compte tenu des différences de fond entre les deux villes, son trait d'union réside dans le fait que tous les deux sont considérés comme centres vitales pour la gouvernance de leurs régions respectives, en rassemblant les pouvoirs régionaux, exécutif et législatif.

Mots-CLÉs: Merida; Pamplona; capitale régionale; dynamique de la population; emploi; logement. 